\title{
Stability Fluctuations of Plasmid-bearing Cells: Immobilization Effects
}

\author{
By MONCEF NASRI, ${ }^{*}$ FADWA BERRY, SAMI SAYADI, \\ DANIEL THOMAS AND JEAN N. BARBOTIN \\ Laboratoire de Technologie Enzymatique, UA Numero 523 du Centre National de la Recherche \\ Scientifique, Université de Technologie de Compiègne, BP 649, 60206 Compiègne Cedex, France
}

(Received 10 February 1988; revised 11 April 1988)

The maintenance of the plasmid vectors pTG201 and pTG206 (which both carry the Pseudomonas putida $x y l E$ gene) and $\mathrm{pB} \lambda \mathrm{H} 3$ in Escherichia coli hosts was studied in free and immobilized continuous cultures. pTG201, containing the strong $\lambda \mathbf{P}_{\mathbf{R}}$ promoter, was more quickly lost than plasmid pTG206, containing the tetracycline resistance gene promoter. The instability of pTG201 seems to be related to high expression of the cloned $x y l E$ gene. Fluctuations in the proportion of pTG201-containing cells were observed in the free system, suggesting the appearance of adaptive descendants (with and without plasmid) from the initial strains. The loss of plasmid vectors from $E$. coli cells and the fluctuations in the proportion of plasmid-containing cells could be prevented by immobilizing plasmid-containing bacteria in carrageenan gel beads.

\section{INTRODUCTION}

The integration of strong promoters into cloning vectors is of great importance for achieving high-level expression of cloned genes in Escherichia coli (Remault et al., 1981). The levels of protein synthesis directed by the $\lambda \mathrm{P}_{\mathrm{R}}$ promoter can exceed $25 \%$ of total cell protein (Zabeau \& Stanley, 1982). Unfortunately, high-level expression of the cloned gene can affect adversely the stability of recombinant plasmids (Imanaka et al., 1980; Caulcott et al., 1985). There are two explanations for this: (i) an increase in the frequency of transcriptional initiation directed by the strong promoters could reduce the efficiency of plasmid DNA replication; (ii) elevated expression of the cloned gene could disturb cell metabolism, thus reducing the maximum growth rate of plasmid-containing cells (Inselburg, 1978; Brosius, 1984).

A variety of experimental approaches to overcoming plasmid instability have been proposed (Uhlin et al., 1979; Dally et al., 1981; Tucker et al., 1984; Zurita et al., 1984; Ensley, 1986). The most widely used method is the addition of antibiotic to the culture medium, but in a large-scale preparation this would be expensive. Plasmid stability may also be enhanced by the cloning of the partitioning locus, which apparently stabilizes the partitioning of plasmids into daughter cells (Meacock \& Cohen, 1980; Miller et al., 1983). However, the par locus does not stabilize all plasmid vectors (Hinchliffe et al., 1983). A general method of ensuring plasmid stability is the use of immobilized plasmid-containing cells. Earlier work (Jaoua et al., 1986; Nasri et al., $1987 a$; Sayadi et al., 1987) has shown that the immobilization of plasmid-containing cells considerably increases the stability of plasmid DNA. In this paper, the stability of several plasmid vectors in free and immobilized $E$. coli cells was examined by continuous culture.

Present address : Laboratoire de Chimie Bactérienne, CNRS de Marseille, 31 Chemin Joseph Aiguier, BP 71, 13277 Marseille. Cedex 9, France.

Abbreviation: C23O, catechol 2,3-dioxygenase.

0001-4692 (C) 1988 SGM 


\section{METHODS}

Bacterial strains and plasmids. The $E$. coli strains used in this study were W3101 (recAl3 Nalr trpE), K12, HB101 and B. The plasmid pTG206 (Apr $\mathrm{Tc}^{\mathrm{s}}$ ) is a derivative of $\mathrm{pBR} 322$ with ligation of the $B a m \mathrm{HI} / \mathrm{XhoI}$ fragment from plasmid pWWO (carrying the $x y l E$ gene coding for catechol 2,3-dioxygenase) to the large segment of pBR322 that remained after double digestion with BamHI and SalI (Zukowski et al., 1983). pTG201 was constructed by ligation of the $B a m \mathrm{HI} / X h o \mathrm{I}$ fragment (mentioned above) to the large segment of $\mathrm{pB} \lambda \mathrm{H} 3$ that remained after double digestion with $B g l \mathrm{I}$ and $S a l \mathrm{I} . \mathrm{pB} \lambda \mathrm{H} 3\left(\mathrm{Ap}^{\mathrm{r}} \mathrm{Tc}^{\mathrm{s}}\right)$ is a derivative of $\mathrm{pBR} 322$ which contains the $\lambda \mathrm{P}_{\mathrm{R}}$ promoter and the $c 1857$ repressor. The plasmids were introduced into $E$. coli cells by transformation using the $\mathrm{CaCl}_{2}$ procedure (Mandel \& Higa, 1970). Transformants were selected by ampicillin $\left(50 \mu \mathrm{g} \mathrm{ml}^{-1}\right)$ resistance of host cells. pB $\lambda$ H3, pTG201 and pTG206 were generously donated by Transgene SA.

Immobilization procedure. Immobilized growing cells were prepared using the method of Takata et al. (1977). A $0.5 \mathrm{ml}$ sample from a preculture was added to $9.5 \mathrm{ml} 2.1 \%(\mathrm{w} / \mathrm{v}) \mathrm{K}$-carrageenan E407 (CECA, France) and suspended by stirring at $42^{\circ} \mathrm{C}$. This mixture was pumped at a rate of approximately $2 \mathrm{ml} \mathrm{min}^{-1}$ into $40 \mathrm{ml} \mathrm{LB}$ medium containing $0 \cdot 3 \mathrm{M}-\mathrm{KCl}$, thus forming beads with a diameter of about $3 \mathrm{~mm}$.

Media. The medium used throughout the experiments was L broth (LB: $1 \%$, w $/ \mathrm{v}$, tryptone, $0.5 \%$ yeast extract, $0.5 \% \mathrm{NaCl}$ ). For immobilized cells, LB medium was supplemented with $0.1 \mathrm{M}-\mathrm{KCl}$. Agar was added to LB medium to prepare LB agar plates.

Cultivation conditions. Continuous culture experiments were done in $50 \mathrm{ml}$ volumes in $100 \mathrm{ml}$ glass vessels that were maintained at $37^{\circ} \mathrm{C}$, with aeration at $170 \mathrm{ml} \mathrm{min}^{-1}$. The fermenter was stirred continuously at 250 r.p.m. For free cultures, experiments were generally started with an overnight batch culture in $20 \mathrm{ml} \mathrm{LB}$ medium containing ampicillin $\left(50 \mu \mathrm{g} \mathrm{ml}^{-1}\right)$. The chemostat was then inoculated with $0.4 \mathrm{ml}$ of this culture. After batch growth for 4-5 h, fresh medium flow was started at the desired dilution rate. For immobilized culture, the gel beads formed were transferred to the chemostat, and immediately a continuous flow of LB medium was initiated.

Determination of plasmid stability. Samples were withdrawn from the continuous cultures, diluted and plated onto LB agar plates. The proportions of cells containing pTG201 and pTG206 were calculated by spraying the bacterial colonies with an aqueous solution of $0.5 \mathrm{M}$-catechol. A yellow colour indicated a catechol-2,3dioxygenase-producing colony (Zukowski et al., 1983). For immobilized cells, gel beads were washed twice with $0.8 \% \mathrm{NaCl}$, then dissolved in $1 \%$ sodium citrate.

Assay for catechol 2,3-dioxygenase (C23O). The conversion by $\mathrm{C} 23 \mathrm{O}$ (EC 1.13.11.2) of catechol to a yellow product, 2-hydroxymuconic semialdehyde, was determined spectrophotometrically as described by Sala-Trepat \& Evans (1971).

Plasmid isolation. Plasmid DNA was extracted from the cells according to Birnboim \& Doly (1979).

Gel electrophoresis of nucleic acids. Horizontal slab gels of $1 \%(\mathrm{w} / \mathrm{v})$ agarose were used. The DNA bands were visualized under ultraviolet light after staining with ethidium bromide $\left(1 \mu \mathrm{g} \mathrm{ml}^{-1}\right)$ for $30 \mathrm{~min}$.

\section{RESULTS}

\section{Transformation with recombinant plasmids}

E. coli $\mathrm{B}, \mathrm{HB} 101, \mathrm{~K} 12$ and W3101 were transformed with pTG201 (purified from $E$. coli BZ18), pTG206 and pB $\lambda \mathrm{H} 3$ (purified from E. coli C600). Several transformants $\left(\mathrm{Ap}^{\mathrm{r}} \mathrm{XylE}^{+}\right.$) were selected and grown in $50 \mathrm{ml} \mathrm{LB}$ medium containing ampicillin, and the presence of the plasmids was verified directly by plasmid isolation (Fig. 1). The plasmids purified from the different transformants were shown to be identical to the originals by digestion with EcoRI (data not shown).

\section{Stability of recombinant plasmids in free continuous cultures}

The stability of plasmid-containing $E$. coli strains was examined in free continuous cultures at a dilution rate of $1.35 \mathrm{~h}^{-1}$. When grown in continuous cultures in the absence of antibiotic selection, $E$. coli cells carrying pTG206 (which expresses the $x y l E$ gene from the tetracycline resistance gene promoter) proved to be stable in LB medium but expressed very low levels of $\mathrm{C} 23 \mathrm{O}$ (Fig. 2). The expression of $\mathrm{C} 23 \mathrm{O}$ did not appear to affect the stable maintenance of pTG206 in the culture. Only $2 \%$ and $4 \%$ of E. coli B and E. coli W3101 had lost pTG206 after 270 generations.

The stability of plasmid $\mathrm{pB} \lambda \mathrm{H} 3$ was also investigated in $E$. coli cells grown in the absence of antibiotic selection. This plasmid was $100 \%$ stable for more than 300 generations in both $E$. coli $\mathrm{B}$ and $E$. coli $\mathrm{W} 3101$.

In order to express $\mathrm{C} 23 \mathrm{O}$ at high levels in $E$. coli cells, the $x y l E$ gene was inserted into the 

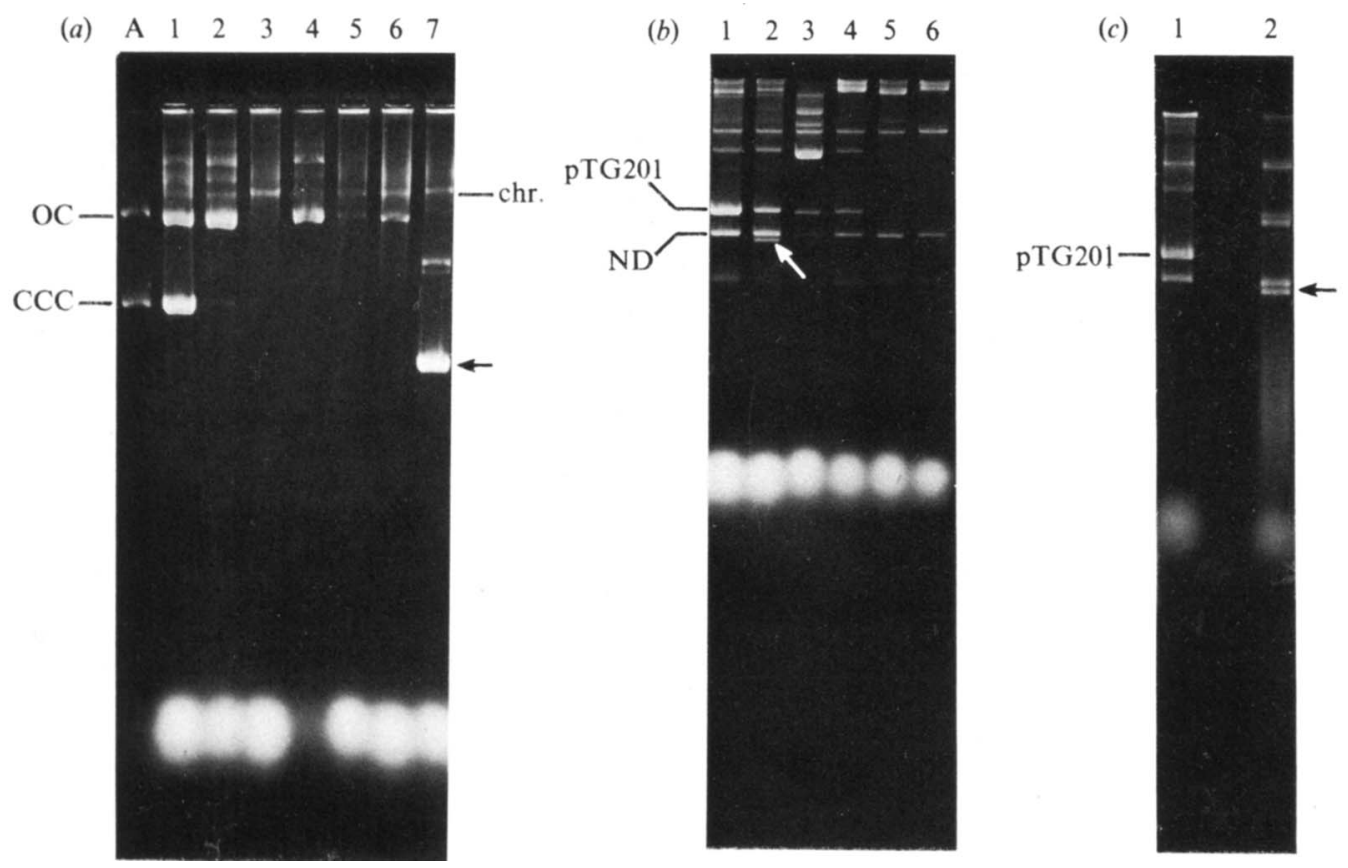

Fig. 1. Agarose gel electrophoresis of plasmid DNA extracted from $E$. coli cells. (a). A, ColE1 DNA $(6440 \mathrm{bp})$ (this DNA, which is approximately the same size as pTG201, was used as a reference); 1 , W3101(pTG201); 2, BZ18(pTG201); 3, B strain carrying no plasmid; 4, B(pTG201); 5 and 6, HB101(pTG201); 7, B strain carrying modified pTG201. (b) 1, K12(pTG201); 2, plasmid DNA isolated from K12(pTG201) after about 30 generations of cell growth (note the appearance of a band representing modified pTG201); 3, BZ18(pTG201); 4, K12 which has retained pTG201 during culture; $5, \mathrm{~K} 12$ which has lost pTG201 during culture; $6, \mathrm{~K} 12$ without the introduction of pTG201. (c) 1 , K12(pTG201); 2, K12 carrying modified pTG201. Arrows indicate bands representing modified pTG201. OC, open circular plasmid DNA; CCC, covalently closed circular plasmid DNA; chr., chromosomal DNA; ND, plasmid DNA of undetermined topology.

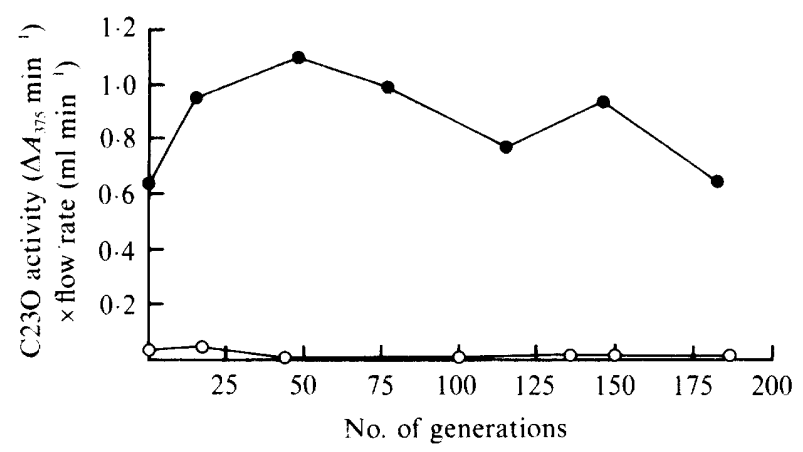

Fig. 2. Activities of $\mathrm{C} 23 \mathrm{O}$ in $E$. coli B containing pTG206 (O) and pTG201

$\mathrm{pB} \lambda \mathrm{H} 3$ vector, which carries the strong $\lambda \mathbf{P}_{\mathrm{R}}$ promoter controlled by the thermosensitive $c I 857$ repressor gene product (Lieb, 1966). Fig. 2 shows that cells containing the resulting plasmid, pTG201, produced much more C23O (50-fold) than cells carrying pTG206. However, in contrast with pTG206, pTG201 was not stably maintained in a free system (Fig. 3). We concluded that the instability of the recombinant plasmid pTG201 in E. coli strains is related to the high expression level of the $x y l E$ gene. 


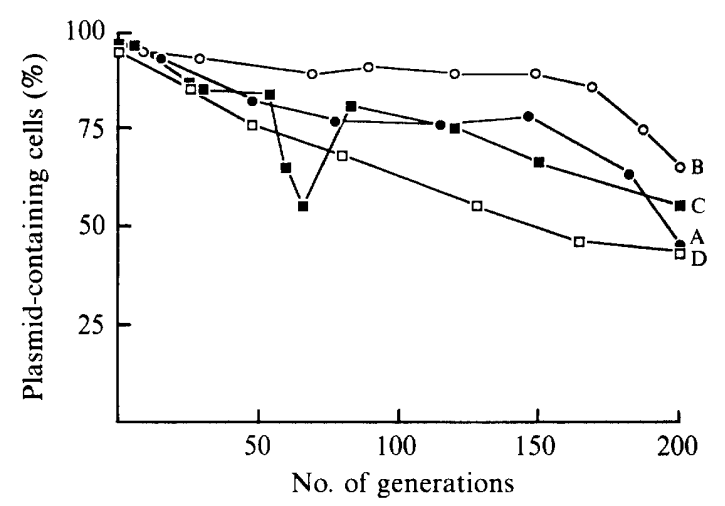

Fig. 3. Stability of maintenance of pTG201 in free E. coli B cells grown in continuous culture. Four experiments, A, B, C and D, were done under identical conditions of growth $\left(D=1.35 \mathrm{~h}^{-1}\right.$, temperature $\left.=37^{\circ} \mathrm{C}\right)$. The initial proportion of cells carrying pTG201 $(t=0)$ was $97 \%$ in each case. Each point was determined from 1500 to 2000 colonies growing on LB agar plates as described in Methods. The standard errors were within $2 \%$ of the mean.

\section{Fluctuation in the fraction of pTG201-containing organisms}

In a previous paper (Nasri et al., 1987a), we showed that pTG201 was maintained with various degrees of stability in the different $E$. coli hosts tested. The results in Fig. 3 show that the kinetics of pTG201 loss from E. coli B cells varied from experiment to experiment. In a first experiment (Fig. 3, A), 75\% of E. coli B cells maintained pTG201 after 150 generations. Thereafter, there was a dramatic decline to give $45 \%$ pTG 201 -carrying cells at 200 generations. In a second experiment, under the same conditions, only 7\% of the host cells had lost pTG201 after 150 generations, but a significant loss of pTG201 was again detected after prolonged incubation (Fig. 3, B). In a third experiment (Fig. 3, C) the proportion of plasmid-carrying cells decreased gradually during the first 55 generations, then decreased dramatically, increased and declined again. In a fourth experiment, the apparent plasmid loss was $50 \%$ after 140 generations (Fig. 3, D), compared with 22,11 and $30 \%$ after the same time of incubation in experiments A, B and $\mathrm{C}$, respectively. It is well known that under non-selective growth conditions, plasmid-free cells arise in the population relatively rapidly. On the other hand, several workers have reported that plasmid-containing cells have lower maximum specific growth rates than plasmid-free cells, so that the proportion of plasmid-containing cells decreases (Engberg \& Nordström, 1975; Godwin \& Slater, 1979). Such fluctuations of plasmid-containing cells suggest the appearance of host cells (with or without plasmid) which were more or less adapted for growth under the conditions used than the rest of the population. In fact, two strains, $E$. coli $\mathrm{B}^{*}$ and $E$. coli $\mathrm{B}^{* *}$ (both without pTG201), were isolated at the 180th and 215th generations, respectively, from the culture described in Fig. 3, B. The growth rates of these plasmid-free descendants, measured in batch culture in LB medium $\left(2.5 \mathrm{~h}^{-1}\right.$ for $E$. coli $\mathrm{B}^{*}$ and $2.7 \mathrm{~h}^{-1}$ for $E$. coli $\left.\mathrm{B}^{* *}\right)$ were different from that of the original plasmid-free strain B $\left(2 \cdot 61 \mathrm{~h}^{-1}\right)$. The growth rate of $E$. coli B carrying pTG201 was $2.45 \mathrm{~h}^{-1}$.

\section{Stability of recombinant plasmids in immobilized continuous cultures}

The dilution rate of the immobilized cell culture $\left(3.4 \mathrm{~h}^{-1}\right)$ was higher than the maximum growth rate. Under these conditions, the growth rate of immobilized cells was at least equal to the maximum growth rate obtained in batch cultures. The high dilution rate used should rapidly remove any released cells present in the medium and prevent them dividing in the reactor. In contrast with free cells, immobilized and 'leaked' (released from the gel due to the rapid growth of cells near the gel surface) plasmid-containing cells exhibited a high stability. As with pTG201 
(Nasri et al., 1987a), pTG206 and pB $\lambda \mathrm{H} 3$ were extremely stable in both $E$. coli strains tested (B and W3101). No loss of these plasmids was detected even after 400 generations. In addition, fluctuations in the fraction of the bacterial population that retained the recombinant plasmid were not observed.

\section{Loss of C23O activity is essentially due to segregational instability}

Loss of expression of plasmid-encoded genes is due to either (i) segregational instability (loss of the whole recombinant plasmid) (Skogman et al., 1983; Miwa et al., 1984) or (ii) structural instability (loss of part or all of the cloned DNA from the plasmids) (Rood et al., 1980). Either phenomenon will contribute to plasmid instability and consequently to a decrease in production of the plasmid-coded gene product.

We previously reported that no $\mathrm{Ap}^{r} \mathrm{XylE}^{-}$colonies were found with $E$. coli W3101(pTG201) and $E$. coli B(pTG201) (Nasri et al., 1987a). The experiments were repeated, but with a larger number of colonies, using $E$. coli strains B, K12 and W3101 carrying pTG201. Several thousand $\mathrm{XylE}^{-}$colonies were tested for antibiotic resistance. Most of the segregants were $\mathrm{Ap}^{\mathrm{s}} \mathrm{XylE}^{-}$; such cells had lost pTG201, since no plasmid DNA was found. No $\mathrm{Ap}^{s} \mathrm{XylE}^{+}$segregants were detected. In contrast, $\mathrm{Ap}^{r} \mathrm{XylE}^{-}$segregants were detected but with low frequency. One explanation for this could be the deletion of the $x y l E$ gene. Plasmid DNA was extracted from these $\mathrm{Ap}^{\mathrm{r}} \mathrm{XylE}^{-}$colonies and analysed by agarose gel electrophoresis (Fig. 1). Figs $1($ a) lane 7, $1(b)$ lane 2 and $1(c)$ lane 2 show single plasmid bands, running more rapidly than pTG201, from cells of $E$. coli B and $E$. coli $\mathrm{K} 12$. The sizes of these modified plasmids were estimated from the mobilities of the plasmid bands and from restriction enzyme digests (not shown) to be approximately $4700 \mathrm{bp}$ in the case of $E$. coli $\mathrm{B}$ and $5000 \mathrm{bp}$ in the case of $E$. coli $\mathrm{K} 12$. These observations suggest that the $\mathrm{Ap}^{\mathrm{r}} \mathrm{XylE}^{-}$segregants might contain plasmids deleted in the region covering the $x y l E$ gene.

With pTG206, the loss of the two plasmid markers (ampicillin resistance and the $x y l E$ gene) was invariably accompanied by loss of detectable plasmid.

\section{DISCUSSION}

The maintenance of $\mathrm{pB} \lambda \mathrm{H} 3$ and pTG206 in our experiments under all conditions tested could be explained by (i) the higher copy number of these plasmids (about 50 copies per cell), so that the rates of loss of these vectors from host cells were low, or (ii) the absence of competition between plasmid-free (once appeared) and plasmid-containing cells, since the maximum growth rates of these strains were similar.

With pTG201, expression of $x y l E$ gene might be increased by readthrough transcription from the strong $\lambda \mathrm{P}_{\mathrm{R}}$ promoter. Our results showed that the $\lambda \mathrm{P}_{\mathrm{R}}$ promoter can direct the production of 50 times more $\mathrm{C} 23 \mathrm{O}$ than could the tetracycline resistance gene promoter. The increased level of expression of the $x y l E$ could be responsible, at least in part, for the instability of the plasmid.

With pTG206, the plasmid markers (ampicillin resistance and $x y l E$ gene) are always simultaneously lost. With pTG201, the absence of $\mathrm{C} 23 \mathrm{O}$ activity is essentially due to segregational instability. $\mathrm{Ap}^{\mathrm{r}} \mathrm{XylE}^{-}$segregants were isolated as spontaneous mutants by plating about $10000 \mathrm{XylE}^{-}$cells onto agar plates containing ampicillin (less than $0 \cdot 1 \%$ are $\mathrm{Ap}^{\mathrm{r}} \mathrm{XylE}^{-}$).

Immobilization of the plasmid-containing cells considerably increases the stability of pTG201 and pTG206 recombinant plasmids. The stability of pBR322 and a number of close derivatives (pBR328 and pBR325) was also enhanced in continuous cultures with immobilized plasmid-containing cells (results not shown).

A plausible explanation for the fluctuations of plasmid-containing cells is the appearance of more competitive descendants (with or without pTG201) originating from plasmid-containing cells. Such kinetics of plasmid loss have been previously described (Helling et al., 1981; Jones \& Melling, 1984; Keshavarz et al., 1985). The authors attributed fluctuations to a replacement of the initial plasmid-containing cells by more competitive plasmid-containing descendants, resulting from chromosomal mutations. This fluctuation is not observed in the immobilized-cell culture. In a previous paper (Nasri et al., 1987 b), we showed that inside the gel beads, plasmid- 
containing cells grow in the outer layer, for 10 to 16 generations, where they form microcolonies. This number of generations is not sufficient for adaptive mutants to appear within the cavities of the gel beads, judging by the results in the free system, in which adaptive mutants appeared only after prolonged incubation.

In conclusion, the data presented in this paper outline a simple non-selective method for improving the stability of vectors used to overproduce gene products. The immobilization method stabilizes all plasmid vectors that we have tested. This increased plasmid stability observed in immobilized cells may have resulted from the mechanical properties of the gel bead system, which perhaps only allows a limited number of cell divisions to occur in each clone of cells before the clone escapes from the gel bead.

We thank J. P. Lecocq (Transgene SA) for providing pB $\lambda$ H3, pTG201 and pTG206 plasmids, and M. L. Gaudin for plasmid isolation.

\section{REFERENCES}

Birnboim, H. C. \& Doly, J. (1979). A rapid alkaline extraction procedure for screening recombinant plasmid DNA. Nucleic Acids Research 7, 15131523.

Brosius, J. (1984). Toxicity of an overproduced foreign gene product in Escherichia coli and its use in plasmid vectors for the selection of transcription terminators. Gene 27, 161-172.

Caulcott, C. A., Lilley, G., Wright, E. M., Robinson, M. K. \& Yarranton, G. T. (1985). Investigation of the instability of plasmids directing the expression of Met-prochymosin in Escherichia coli. Journal of General Microbiology 131, 3355-3365.

Dally, E. L., Eveleigh, D. E., MonTenecourt, B. S., Stokes, H. W. \& Williams, R. L. (1981). Recombinant DNA technology. Food Technology 35, 26-33.

ENGBERG, B. \& NoRDSTRÖM, K. (1975). Replication of R-factor R1 in Escherichia coli K-12 at different growth rates. Journal of Bacteriology 123, 179-186.

ENSLEY, B. D. (1986). Stability of recombinant plasmids in industrial microorganisms. CRC Critical Reviews in Biotechnology 4, 263-277.

Godwin, D. \& Slater, J. H. (1979). The influence of the growth environment on the stability of a drug resistance plasmid in Escherichia coli K12. Journal of General Microbiology 111, 201-210.

Helling, R. B., Kinney, T. \& Adams, J. (1981). The maintenance of plasmid-containing organisms in populations of Escherichia coli. Journal of General Microbiology 123, 129-141.

Hinchliffe, E., Kuempel, P. L. \& Masters, M. (1983). Escherichia coli minichromosomes containing the pSC101 partitioning locus are not stably inherited. Plasmid 9, 286-297.

Imanaka, T., Tsunekawa, H. \& Aiba, S. (1980). Phenotypic stability of trp recombinant plasmids in Escherichia coli. Journal of General Microbiology 118 , 579-584.

INSELBURG, J. (1978). ColE1 plasmid mutants affecting growth of an Escherichia coli $r e c \mathrm{~B} r e c \mathrm{C} s b c \mathrm{~B}$ mutant. Journal of Bacteriology 133, 433-436.

JaOUA, S., Breton, A. M., Younes, G. \& GuespinMiCHEL, J. (1986). Structural instability and stabilization of IncP-1 plasmids integrated into the chromosome of Myxococcus xanthus. Journal of Biotechnology 4, 313-323.
JoNeS, S. A. \& Melling, J. (1984). Persistence of pBR322 related plasmids in Escherichia coli grown in chemostat cultures. FEMS Microbiology Letters 22, 239-243.

Keshavarz, T., Lilly, M. D. \& Clarke, P. M. (1985). Stability of a catabolic plasmid in continuous culture. Journal of General Microbiology 131, 11931203.

LIEB, M. (1966). Studies of heat inducible lambda bacteriophage. I. Order of genetic sites and properties of mutant prophages. Journal of Molecular Biology 16, 149-163.

MANDEL, M. \& HigA, A. (1970). Calcium dependent bacteriophage DNA infection. Journal of Molecular Biology 53, 159--162.

Meacock, P. A. \& Cohen, S. N. (1980). Partitioning of bacterial plasmids during cell division. A cis-acting locus that accomplishes stable plasmid inheritance. Cell 20, 529-542.

Miller, C. A., Tucker, W. T., Meacock, P. A., Gustafsson, P. \& COHEN, S. N. (1983). Nucleotide sequence of the partition locus of Escherichia coli plasmid pSC101. Gene 24, 309-315.

Miwa, K., Nakamori, S., Sano, K. \& Momose, H. (1984). Stability of recombinant plasmids carrying the threonine operon in Escherichia coli. Agricultural and Biological Chemistry 48, 2233-2237.

NASRi, M., SAYAdI, S., Barbotin, J. N., Dhulster, P. $\&$ Thomas, D. (1987a). The influence of immobilization on the stability of pTG201 recombinant plasmid in some strains of Escherichia coli. Applied and Environmental Microbiology 53, 740-744.

NasRi, M., Sayadi, S., Barbotin, J. N. \& Thomas, D. $(1987 \mathrm{~b})$. The use of the immobilization of whole living cells to increase stability of recombinant plasmids in Escherichia coli. Journal of Biotechnology 6, 147-157.

Remault, E., Stanssens, P. \& Fiers, W. (1981). Plasmid vectors for high-efficiency expression controlled by the $\mathrm{P}_{\mathrm{L}}$ promoter of coliphage lambda. Gene 15, 81-93.

Rood, J. I., SNeddon, M. K. \& Morrison, J. F. (1980). Instability in tyr R strains of plasmids carrying the tyrosine operon: isolation and characterization of plasmid derivatives with insertions or deletions. Journal of Bacteriology 144, 552-559. 
Sala-Trepat, J. M. \& Evans, W. C. (1971). The meta cleavage of catechol by Agrobacter species 4oxalocrotonate pathway. European Journal of Biochemistry 20, 400-413.

SAyadi, S., NASRI, M., Berry, F., Barbotin, J. N. \& THOMAS, D. (1987). Effect of temperature on the stability of plasmid pTG201 and productivity of $x y l E$ gene product in recombinant Escherichia coli: development of a two-stage chemostat with free and immobilized cells. Journal of General Microbiology 133, 1901-1908.

Skogman, L. G., Nilsson, J. \& Gustafsson, P. (1983). The use of a partition locus to increase stability of tryptophan-operon-bearing plasmids in Escherichia coli. Gene 23, 105-115.

Takata, I., Tosa, T. \& Chibata, I. (1977). Screening of matrix suitable for immobilization of microbial cells. Journal of Solid Phase Biochemistry 2, 225-236.

Tucker, W. T., Miller, C. A. \& Cohen, S. N. (1984). Structural and functional analysis of the par region of the pSC101 plasmid. Cell 38, 191-201.
Uhlin, B. E., Molin, S., Gustafsson, P. \& NordSTRÖM, K. (1979). Plasmids with temperaturedependent copy number for amplification of cloned genes and their products. Gene 6, 91-106.

Zabeau, M. \& STANley, K. K. (1982). Enhanced expression of Cro- $\beta$-galactosidase fusion proteins under the control of the $\mathrm{P}_{\mathrm{R}}$ promoter of bacteriophage $\lambda$. EMBO Journal 1, 1217-1224.

Zurita, M., Bolivar, F. \& Soberon, X. (1984). Construction and characterization of new cloning vehicles. VII. Construction of plasmid pBR327par, a completely sequenced, stable derivative of pBR327 containing the par locus of pSC101. Gene 28, 119122.

Zukowski, M. N., Gaffney, D. F., Speck, D., Kauffman, M., Findeli, A., Wisecup, A. \& LECOCQ, J. P. (1983). Chromogenic identification of genetic regulatory signals in Bacillus subtilis based on expression of a cloned Pseudomonas gene. Proceedings of the National Academy of Sciences of the United States of America 80, 1101-1105. 